\title{
Is Catalase Activity One of the Factors Associated with Maize Resistance to Aspergillus flavus?
}

\author{
Zenaida V. Magbanua, ${ }^{1}$ Consuelo M. De Moraes, ${ }^{2}$ T. D. Brooks, ${ }^{3}$ W. Paul Williams, ${ }^{3}$ and Dawn S. Luthe ${ }^{4}$ \\ ${ }^{1}$ Department of Plant and Soil Sciences, Box 9555, Mississippi State University, MS 39762, U.S.A.; ${ }^{2}$ Department of \\ Entomology, 535 ASI, Pennsylvania State University, University Park, PA 16802, U.S.A.; ${ }^{3}$ USDA, ARS, Corn Host Plant \\ Resistance Research Unit, Box 5367, Mississippi State, MS 39762, U.S.A.; ${ }^{4}$ Department of Crop and Soil Sciences, 116 \\ ASI, Pennsylvania State University, University Park, PA 16802, U.S.A.
}

Submitted 14 September 2006. Accepted 3 January 2007.

\begin{abstract}
Plant responses to biotic and abiotic stresses are usually accompanied by the release of reactive oxygen species including hydrogen peroxide. Hydrogen peroxide plays a direct role in defense and is involved in many signal transduction pathways that lead to the proliferation of other defenses. Because catalase helps to maintain reactive oxygen homeostasis during biotic and abiotic stress, its activity was measured in various cob tissues during maize ear development. Catalase activity was determined in immature and mature embryos, pericarp, and rachis tissues of maize lines that are resistant and susceptible to Aspergillus flavus infection. The effect of fungal inoculation on catalase activity was also measured. Over two years of field experimentation, a correlation was observed between resistance and the level of catalase-specific activity in immature embryos, which was significantly higher in resistant lines $(P<0.0001)$. Furthermore, catalase activity in the resistant lines was significantly higher in immature embryos from inoculated ears $(P=$ 0.0199). No correlation was observed between resistance and catalase activity in other ear tissues. Levels of hydrogen peroxide, the catalase substrate, and salicylic acid in the embryo were also determined. The resistant lines showed lower levels of $\mathrm{H}_{2} \mathrm{O}_{2}(P<0.0001)$ and higher levels of salicylic acid $(P<$ 0.0001) as compared with the susceptible lines. Catalase 3 was sequenced from the aflatoxin-resistant (Mp313E) and susceptible (SC212m) inbreds. The predicted amino acid sequence indicated that there was a 20 -aa deletion in the resistant inbred that might affect enzymatic activity. Unlike many plant-pathogen interactions, it appears that lowering $\mathrm{H}_{2} \mathrm{O}_{2}$ levels helps to prevent $A$. flavus infection and subsequent aflatoxin accumulation.
\end{abstract}

Additional keywords: oxidative stress.

The production of reactive oxygen species (ROS) in response to pathogen attack is one of the hallmarks of plant defense. ROS are formed by the incomplete reduction of oxygen to water, resulting in the production of superoxide, hydroxyl radical and hydrogen peroxide. Generally, ROS accumulation leads to increased salicylic acid (SA) synthesis, the hypersensitive response (HR) and programmed cell death at the site of

Corresponding author: D. S. Luthe; Telephone: +1.814 .863 .3542 ; Fax: +1.814.863.7043. E-mail: ds114@psu.edu

* The $\boldsymbol{e}$-Xtra logo stands for "electronic extra" and indicates that Figure 1 appears in color online. infection, and subsequent induction of pathogenesis-related genes (Dempsey et al. 1999; Lamb and Dixon 1997). In some cases, pathogen attack activates defenses distal to the infection site called systemic acquired resistance (Dempsey et al. 1999; Lamb and Dixon 1997). Hydrogen peroxide $\left(\mathrm{H}_{2} \mathrm{O}_{2}\right)$, one of the ROS molecules formed, inhibits the growth and viability of diverse microbial pathogens (Kiraly et al. 1993; Peng and Kuc 1992; Wu et al. 1995) and, more importantly, is believed to act as a diffusible signal that induces downstream defense proteins. During the $\mathrm{HR}, \mathrm{H}_{2} \mathrm{O}_{2}$ is the substrate for the oxidative crosslinking of proline-rich structural proteins and is a trigger for hypersensitive cell death (Bradley et al. 1992; Breusegem et al. 2001; Brisson et al. 1994; Lamb and Dixon 1997; Scandalios 1994; Xiong et al. 2002). The generation of $\mathrm{H}_{2} \mathrm{O}_{2}$ at the correct time and place hindered successful fungal penetration of plants in three different plant-fungal systems (Mellersh et al. 2002). It is assumed that, with $\mathrm{H}_{2} \mathrm{O}_{2}$ as well as with other ROS, signaling occurs when a target molecule perceives an increase in ROS concentration. The signal induces a change in gene expression, which can result in a change in oxidation state or transcription factor activation (Laloi et al. 2004) and ultimately lead to the activation of specific defenses against pathogens.

Although $\mathrm{H}_{2} \mathrm{O}_{2}$ is essential for signaling pathogen invasion and defense, the accumulation of excess $\mathrm{H}_{2} \mathrm{O}_{2}$ results in oxidative stress that can damage plant tissues. Two enzymes, ascorbate peroxidase and catalase (E.C. 1.11.1.6), remove $\mathrm{H}_{2} \mathrm{O}_{2}$ and modulate oxidative stress (Davletova et al. 2005); Mittler 2002; Mittler et al. 1999; Willekens et al. 1997). Catalase catalyzes the conversion of $\mathrm{H}_{2} \mathrm{O}_{2}$ to water and oxygen and regulates $\mathrm{H}_{2} \mathrm{O}_{2}$ concentration in tissues. This is essential because $\mathrm{H}_{2} \mathrm{O}_{2}$ is a relatively long-lived ROS that has the ability to diffuse widely from the site of its generation and penetrate certain biological membranes. If not eliminated, it can damage cells by reacting with other biomolecules, leading to oxidative stress (Dat et al. 2001). For example, $\mathrm{H}_{2} \mathrm{O}_{2}$ can react with unsaturated fatty acids and the bilayer lipid membranes converting the lipids into lipid peroxides that alter membrane quality, inactivate some membrane proteins, or spontaneously fragment into various toxic compounds, such as reactive electrophiles. Consequently, for a plant tissue to be healthy there must be the correct balance between $\mathrm{H}_{2} \mathrm{O}_{2}$ production and removal.

Catalases are important in plant development, defense, aging, and senescence (Yang and Poovaiah 2002); consequently, they are under strict temporal and spatial regulation. In addition, catalase expression is affected by environmental factors such as light (Boldt and Scandalios 1995), plant hormones (Guan and Scandalios 1998), ozone concentration (Ruzsa et al. 1999), temperature (Auh and Scandalios 1997), xenobiotics (Mylona 
et al. 1998), exogeneously applied $\mathrm{H}_{2} \mathrm{O}_{2}$ (Polidoros and Scandalios 1998), and wounding (Guan and Scandalios 2000). The role of catalase in pathogen defense has been investigated by either overexpressing or suppressing catalase in transgenic plants (Chamnongpol et al. 1998; Dat et al. 2001; Mittler et al. 1999; Vandenabeele, et al. 2004; Willekens et al. 1997). Generally, the suppression of catalase activity results in plants that have higher ROS levels and are primed to resist pathogen attack.

In maize, as in most plants, there are three catalases (Cat1, Cat2, and Cat 3 ) encoded by genes on chromosomes 5, 1, and 4 , respectively (Roupakias et al. 1979). The catalase isozymes share reasonably high sequence similarity at the nucleotide and amino acid levels (63 to $77 \%$ ). The spatial and temporal expression of the isozymes has been characterized using the inbred line W64A (Acevedo and Scandalios 1992; Redinbaugh et al. 1988; Wadsworth and Scandalios 1989). Both Cat1 and Cat 3 are expressed in whole kernels, while Cat 2 was detected only in the late stages of kernel development (Acevedo and
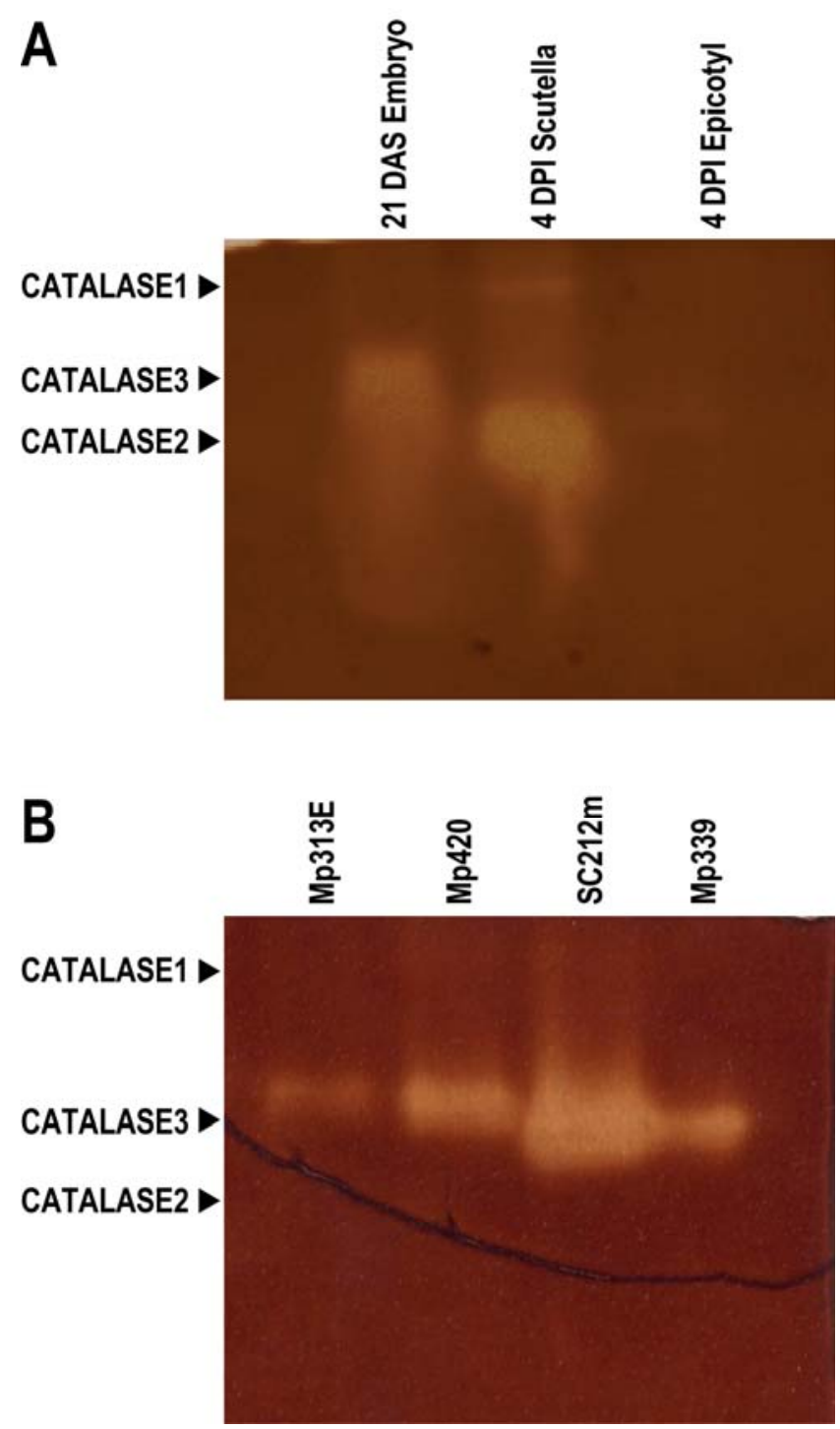

Fig. 1. A, Activity gel showing migration of catalase isozymes in protein extracts from embryos 21 days after silk emergence (DAS), scutella 4 days after imbibition (DPI), and 4-DPI epicotyls from Mp313E. The amount of protein loaded in each lane was 75,60 , and $20 \mathrm{ng}$ for embryos, scutella, and epitcotyls, respectively. B, Catalase activity gel of protein extracts from 25-DAS embryos. The amount of protein loaded for Mp313E, Mp420, SC212m, and Mp339 was 75, 150, 750, and $375 \mathrm{ng}$, respectively.
Scandalios 1992). It was demonstrated that Cat1 and Cat2 are located in the peroxisomes, but the subcellular location of Cat3 is unclear, and it might be localized in the mitochondria (Scandalios 1994). In Arabidopsis, Cat3 has a 16-aa calmodulin-binding domain in the carboxyl region of the protein (Yang and Pooviah 2002). When calmodulin binds this domain, catalase activity increases, thereby decreasing the $\mathrm{H}_{2} \mathrm{O}_{2}$ concentration. It is possible that calmodulin-binding could modulate the level of ROS in response to stress signals. Yang and Pooviah (2002) predicted that this sequence is present in Cat 3 across a number of different species, including maize.

This present study was initiated to investigate the possible role of Cat 3 in maize resistance to alfatoxin, which is a potent mycotoxin produced by the fungus Aspergillus flavus (Chen et al. 2004). Long-term research efforts are aimed at reducing aflatoxin accumulation due to fungal infection in the field during ear development (Anderson et al. 1975). Marker-assisted selection is one of the genetic strategies being used to develop maize inbreds that are resistant to A. flavus infection, aflatoxin accumulation, or both (Brooks et al. 2005). Several resistant inbred lines have been developed (Brooks et al. 2005; Windham and Williams 2002). This resistance is a complex, multigenic, quantitatively inherited trait (Brooks et al. 2005; Naidoo et al. 2002). For example, resistance in Mp313E is influenced by quantitative trait loci (QTL) on chromosomes 1, 2, 3, 4, and 5 (Brooks et al. 2005). Therefore, resistance to aflatoxin accumulation is believed to be a combination of two factors. The first is the plant's ability to resist fungal infection and colonization in the developing ear. The second is the plant's ability to provide an environment in the ear that is unfavorable for aflatoxin synthesis. It has been shown that toxigenic strains of $A$. paraciticus produce aflatoxin in response to oxidative stress (Jayashree and Subramanyam 2000) and aflatoxin accumulation in A. flavus can be reduced by adding phenol antioxidants to the culture medium (Kim et al. 2005, 2006). Walnuts, which naturally produce hydrolyzable tannins, are resistant to aflatoxin accumulation, suggesting that antioxidants in the seed play a protective role (Mahoney and Molyneux 2004). In maize, it has been shown that heat and drought stress, which also produce ROS, trigger aflatoxin production in A. flavusinfected ears (Chen et al. 2004; Payne 1998). Consequently, preventing oxidative stress in the ear might prevent alflatoxin accumulation even though it has been infected with the fungus. One major QTL that accounts for approximately $20 \%$ of the inbred Mp313E's resistance to aflatoxin accumulation was found on chromosome 4 (Brooks et al. 2005). One of the many genes that map in this region is cat3. Because of its role in regulating $\mathrm{H}_{2} \mathrm{O}_{2}$ homeostasis in cells and its map location, we postulated that Cat 3 might contribute to maize resistance to $A$. flavus infection or aflatoxin accumulation. To test this, catalase activity, $\mathrm{H}_{2} \mathrm{O}_{2}$, and $\mathrm{SA}$ levels in developing maize ear tissues were measured. We focused on the embryo because of its importance in maize reproduction and reports suggested it is the primary location of cat 3 in the developing kernel (Scandalios 1994). In addition to determining catalase activity, cat3 from resistant and susceptible inbred lines was sequenced and the predicted amino acid sequences were compared.

\section{RESULTS}

\section{Catalase activity in ear tissues}

from resistant and susceptible inbreds.

Initial experiments were conducted to determine which catalase isozyme was expressed in the embryo. Seeds from Mp313E were imbibed for 4 days, and extracts of the scutella and epicotyl were prepared. At this stage of development, the scutellum expresses Cat 1 and Cat 2 and the etiolated epicotyl expresses 
Cat3 (M. Redinbaugh, personal communication). These samples and an extract from embryos 21 days after silk emergence (DAS) were electrophoresed on a nondenaturing gel and were treated with diaminobenzidine to visualize catalase activity (Fig. 1A). Despite overloading samples, it was difficult to visualize the Cat 3 band in the epicotyl extract. However, the isozyme expressed by the embryo migrated between Cat 1 and Cat 2 in the region that is characteristic of Cat3 (Fig. 1A). This suggests that the major isozyme expressed in the developing embryo is Cat3.

Subsequently, in-gel activity staining was used to visualize catalase activity in immature embryos (25 DAS) from two resistant (Mp313E and Mp420) and two susceptible (SC212m and Mp339) inbreds (Fig. 1). These results also indicated that only one major isozyme, Cat3, was expressed in these embryos. A difference in migration pattern was evident between the resistant and susceptible lines. The isozyme from the two susceptible lines (SC212m and Mp339) migrated faster than the isozyme from the resistant lines. However, to visualize activity on the gel, the amount of protein loaded for Mp420, SC212m, and Mp339 was two-, ten-, and fivefold greater, respectively, than the amount loaded for Mp313E. Consequently, catalase from the two susceptible lines appeared to have lower specific activity than the two resistant lines.

Catalase-specific activity was then quantified in immature and mature embryos, pericarp, and rachis tissues collected from the inbred lines Mp313E, Mp420, SC212m, Mp339,
SC229, and Tx601. Maize ears used for experimentation were grown in the field during summer; hence, each experiment consisted of samples from one year. In the first year, the catalase activity of embryos collected 18, 21, and 25 DAS (which corresponded to 3,6 , and 10 days after inoculation [DAI]) was compared, and embryos from inoculated and uninoculated ears were analyzed at each timepoint. At least three replicates were planned for each timepoint (three inoculated and three controls), but some ears were not successfully pollinated, so some timepoints had fewer or no replicates. A replicate consisted of the embryos from one ear. If an ear did not yield sufficient material, embryos were pooled from several ears. However, embryos from a single ear were never divided to provide more than one replicate. Results of the enzyme activity assay (Fig. 2A) indicated that embryos from resistant lines (Mp313E and Mp420) had significantly higher catalase activity than the susceptible (SC212m) and intermediate (Tx601) lines $(P<0.0001)$ for all sampling dates. In addition, a significant difference $(P<$ $0.01)$ in catalase activity was observed between the two resistant lines, with activity being higher in Mp420 than Mp313E. In the resistant inbred lines, catalase activity tended to increase during embryo development. Differences between genotypes $(P<0.0001)$ and between ears sampled at different ages $(P=$ $0.04)$ were likewise significant. Embryos (21 DAS) from resistant plants that were collected six days after inoculation had significantly higher catalase activity than the uninoculated
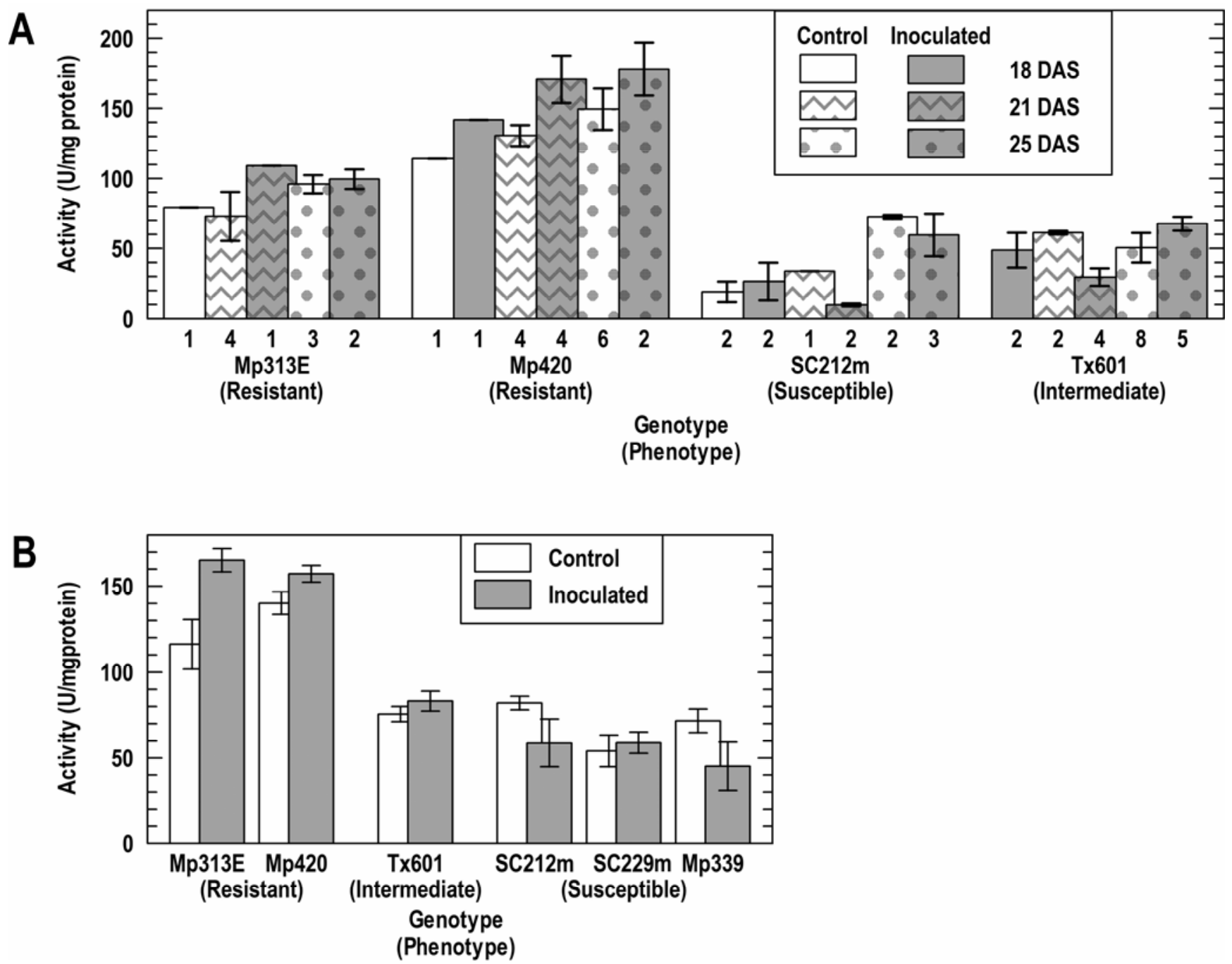

Fig. 2. Catalase activity in A, immature embryos 18, 21, and 25 days after silk emergence (DAS) in the first year and $\mathbf{B}$, 25-DAS immature embryos in the second year of field experimentation. The number of replicates are indicated below the bars. Standard errors are shown. 
control $(P=0.05)$. In the resistant line Mp420, catalase activity in the inoculated embryos tended to be higher at 3,6 , and 10 days after inoculation $(18,21$, and 25 DAS). In the susceptible lines, a significant increase in activity was observed from 18 to
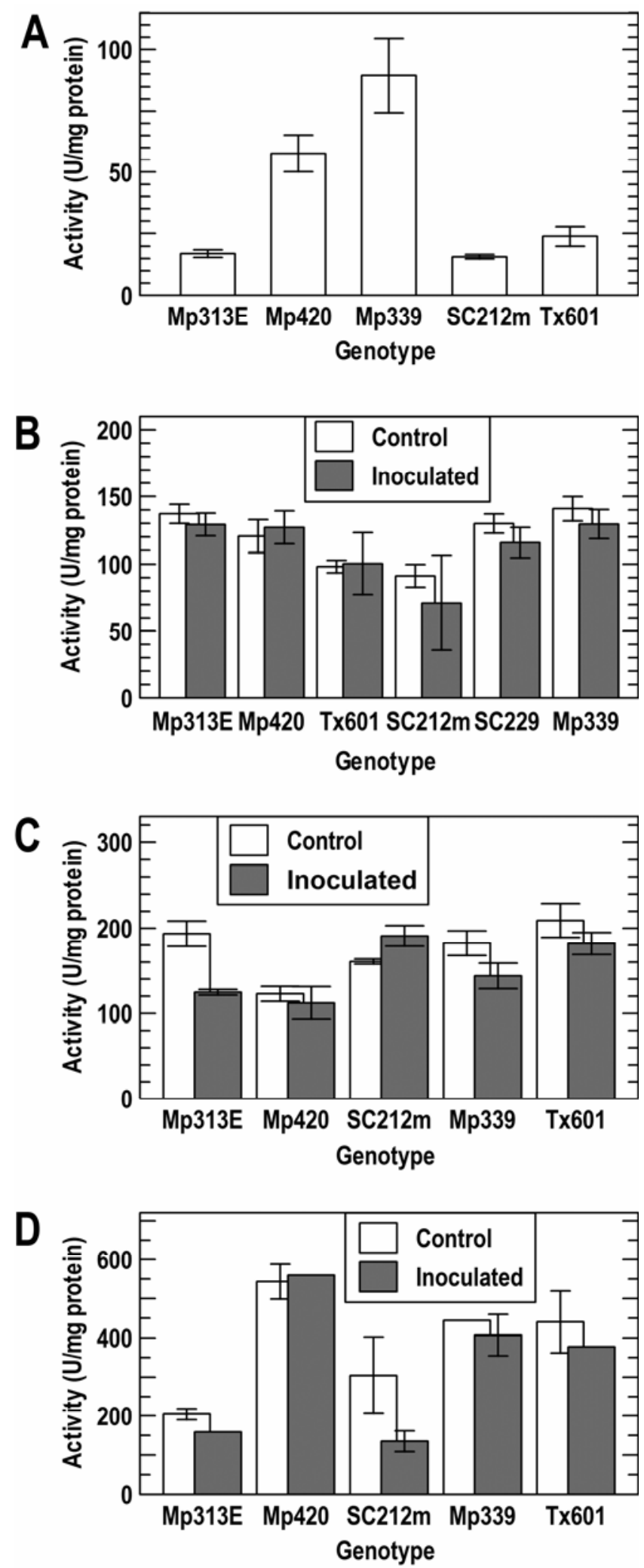

Fig. 3. Catalase activity in mature embryos measured for two years. A, Year 1 and $\mathbf{B}$, year 2. $\mathbf{C}$, In pericarp 25 days after silk emergence (DAS) and D, in 25-DAS rachis tissues. Each datapoint represents three replicates. Standard errors are shown.
25 DAS $(P=0.05)$, but there were no significant differences between inoculated and uninoculated samples.

To determine if differences in catalase-specific activity between resistant and susceptible lines were consistent between years, we selected the timepoint that showed the highest activity (25 DAS) in the first year and collected embryos at that stage in the second year. Also, during the second year of field experimentation, embryos from two additional susceptible lines, SC229m and Mp339, were included in the study. As in the first year, embryos from resistant lines exhibited significantly higher catalase-specific activity than those from susceptible lines $(P<$ 0.0001) (Fig. 2B). Inoculation resulted in higher catalase activity in the two resistant inbred lines $(P=0.002)$ but had no effect on the susceptible lines. When results from both years of experimentation were pooled, catalase activity differed significantly by year $(P=0.0099)$, phenotype $(P<0.0001)$, and genotype $(P=$ $0.01)$. However, catalase activity in the resistant lines did not change significantly from the first year to the second year in 25DAS embryos, suggesting that the environment had little effect on catalase activity in these lines. The resistant lines also showed a significant increase in catalase activity upon inoculation $(P=0.0199)$. The effect of inoculation on catalase activity in susceptible lines, on the other hand, varied from year to year $(P=0.0188)$, suggesting either the absence or inconsistency of such a response in these lines.

We also determined the amount of catalase activity in mature embryos (45 DAS) collected from resistant and susceptible inbreds. In this case, there was no correlation between resistance and catalase activity in either year (Fig. 3A and B). This suggests that catalase functions in resistant embryos in a development stage during which they are most likely to be infected by A. flavus in the field. Catalase activity in pericarp and rachis tissue collected 25 DAS was also determined. Despite the generally high levels of activity found in rachis tissues, no correlation was observed between resistance and catalase activity in pericarp (Fig. 3C) or rachis tissues (Fig. 3D).

\section{$\mathrm{H}_{2} \mathrm{O}_{2}$ levels in 25-DAS embryos.}

Since $\mathrm{H}_{2} \mathrm{O}_{2}$ is the substrate for catalase, its level in 25-DAS embryos from inoculated and uninoculated ears of the inbred lines Mp313E, Mp420, SC212m, Mp339, and Tx601 was determined (Fig. 4). The steady-state $\mathrm{H}_{2} \mathrm{O}_{2}$ levels in resistant lines were lower than those in susceptible lines $(P<0.0001)$. This suggests that higher catalase activity results in lower $\mathrm{H}_{2} \mathrm{O}_{2}$. The inoculation state, on the other hand, had no effect on the steadystate level of $\mathrm{H}_{2} \mathrm{O}_{2}$ in either the resistant or susceptible lines.

\section{SA levels in 25-DAS embryos.}

Because SA has been implicated in the regulation of catalase activity in vivo, the levels of SA in inoculated samples and uninoculated controls of inbred lines Mp313E, Mp420, SC212m, Mp339, SC229, and Tx601 were quantified to determine if there was a relationship between resistance and SA levels (Fig. 5). Significantly higher levels of SA (approximately $100 \mathrm{ng}$ per gram of fresh weight) were found in the two resistant lines than in susceptible lines $(P<0.0001)$. In fact, SA was only detected in one of the four susceptible lines tested (Mp339). The concentration in Mp339 was approximately threefold less than in the resistant inbreds. Jasmonic acid (JA) was also found in the embryos (data not shown), but there were no significant differences among the lines.

\section{Sequence comparison of Cat3}

from resistant and susceptible inbreds.

Because it has been postulated that there is a calmodulinbinding domain in Cat 3 and that calmodulin binding increases its activity (Yang and Pooviah 2002), we wanted to determine 
if there was an alteration in this region of Cat 3 between resistant and susceptible inbreds that might account for the difference in specific activity. The complete cat 3 cDNA sequences including $3^{\prime}$ and $5^{\prime}$ untranslated regions were obtained from Mp313E and SC212m. The predicted amino acid sequences from these two lines were compared with that of Cat 3 from the maize inbred W64A (Fig. 6). Although we have not evaluated the resistance of W64A to A. flavus, the Maize Genetics and Genomics Database does not include it as a resistant phenotype. The predicted amino acids sequences indicated that Cat3 from Mp313E had 475 aa, whereas Cat 3 from SC212m and W64A had 496. A comparison of the derived amino acid sequences of Cat3 from SC212m and W64A reveals a $99.6 \%$ similarity, with only two amino acid differences between the two lines. A comparison of Cat 3 from Mp313E with that of the two susceptible inbreds indicated approximately $94 \%$ similarity. There were five amino acid substitutions between Mp313E, W64A, and SC212m (Fig. 5). The primary difference between the amino acid sequence of the resistant and susceptible lines was a 20-aa deletion in the carboxy-terminal region of Mp313E. This deletion spans amino acids 401 to 421 and is approximately 20 aa upstream from the putative calmodulinbinding site located at amino acids 442 to 455 (Yang and Poovaiah 2002). There are seven proline residues in this region, and four of these are grouped as doublets. The presence of the prolines might increase the rigidity of protein in this region. Although the putative calmodulin-binding site is intact in all three inbreds, the upstream deletion in Mp313E may change the enzyme's conformation, alter the ability of the site to bind calmodulin, and increase its specific activity.

Analysis of the predicted amino acid sequence indicated that Cat3 from Mp313E had a molecular mass of $54.7 \mathrm{kDa}$, an isoelectric point of 6.06 , and a charge of -8.49 at $\mathrm{pH} 7$, while Cat 3 from both SC212m and W64A had a predicted molecular mass of $56.8 \mathrm{kDa}$, an isolectric point of 6.49 , and a charge of -3.49 at $\mathrm{pH}$ 7. The charge differences between Mp313E and $\mathrm{SC} 212 \mathrm{~m}$ may account for the mobility differences in the activity gel (Fig. 1). If the 20-aa sequence is deleted from SC212m or W64E Cat 3 in silico, the predicted isoelectric point and the charge at $\mathrm{pH} 7.0$ changes to 6.14 and -7.49 , respectively. This suggests that the 20-aa deletion alters the electrophoretic mobility of Cat3 from Mp313E. P-Sort bioinformatic analysis (Nakai and Horton 1999) was used to predict subcellular location of Cat 3 . The analysis predicted with greater than $70 \%$ cer-

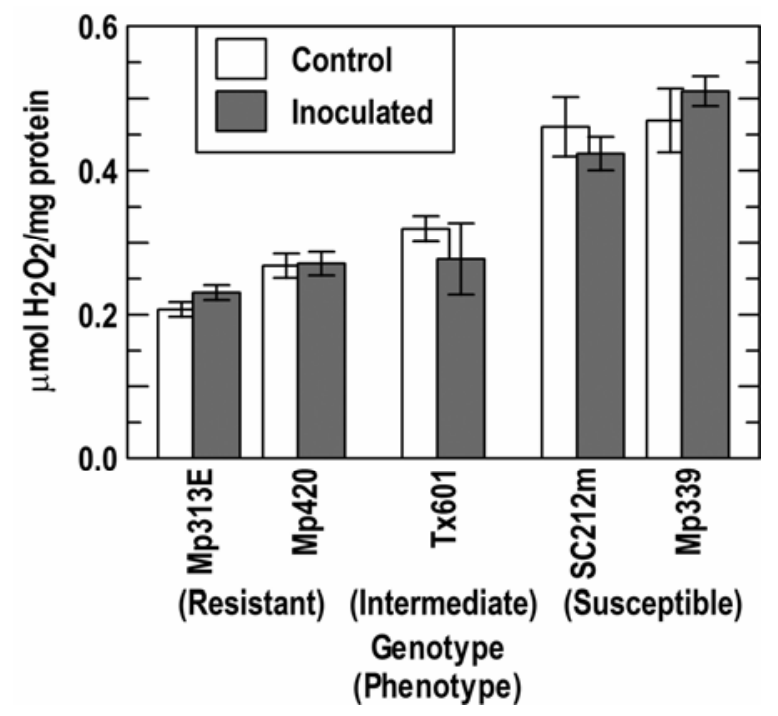

Fig. 4. Steady-state $\mathrm{H}_{2} \mathrm{O}_{2}$ concentration in embryos 25 days after silk emergence. Each datapoint represents five replicates. Standard errors are shown. tainty that Cat3 was localized to the peroxisome for all three inbreds.

\section{DISCUSSION}

Catalase plays a key role in maintaining $\mathrm{H}_{2} \mathrm{O}_{2}$ homeostasis in cells and has been implicated in ROS signaling in response to pathogen attack. Thus, following identification of a QTL on chromosome 4 near the cat 3 map location (Brooks et al. 2005), we hypothesized that Cat 3 was involved in maize resistance to either A. flavus, aflatoxin accumulation, or both. Our first assumption was that catalase activity would be lower in embryos from resistant plants, resulting in the increased accumulation of $\mathrm{H}_{2} \mathrm{O}_{2}$ and triggering defense against $A$. flavus infection. This was not the case; catalase activity was significantly higher in resistant lines, and $\mathrm{H}_{2} \mathrm{O}_{2}$ levels were lower.

Generally, the oxidative burst is an early response to pathogen attack. But A. flavus is a weak pathogen of maize and might not trigger high levels of ROS production. A. flavus produces aflatoxin in response to oxidative stress (Kim et al. 2005), and the inclusion of phenolic antioxidants in media prevents its accumulation (Chipley and Uraih 1980; Kim et al. 2006). Recent reports show that application of abscissic acid, a mediator of plant abiotic stress, or $\mathrm{H}_{2} \mathrm{O}_{2}$ to maize leaves activates a mitogen-activated protein kinase, which enhanced the expression of antioxidant genes, including Cat1 (Zhang et al. 2006). In addition, catalase activity was increased. Since aflatoxin contamination of maize typically occurs in climates in which plants undergo heat and drought stress during grain filling and maturation (Chen et al. 2004), our hypothesis is that oxidative stress in the ear tissues resulting from these environmental stresses triggers aflatoxin accumulation when the fungus is present. Consequently, to reduce aflatoxin accumulation, the kernel must strike a balance in the oxidative state that is sufficient to inhibit fungal growth but low enough to prevent oxidative stress that triggers aflatoxin synthesis. High catalase activity in the embryo may help maintain this balance by preventing the production of excess $\mathrm{H}_{2} \mathrm{O}_{2}$ and thereby reducing aflatoxin accumulation. It may also prevent oxidative damage to the embryo that would make it more susceptible to fungal colonization.

Comparison of the catalase-specific activities in different ear tissues revealed a correlation between resistance and activity only in immature embryos. Since the fungus typically infects

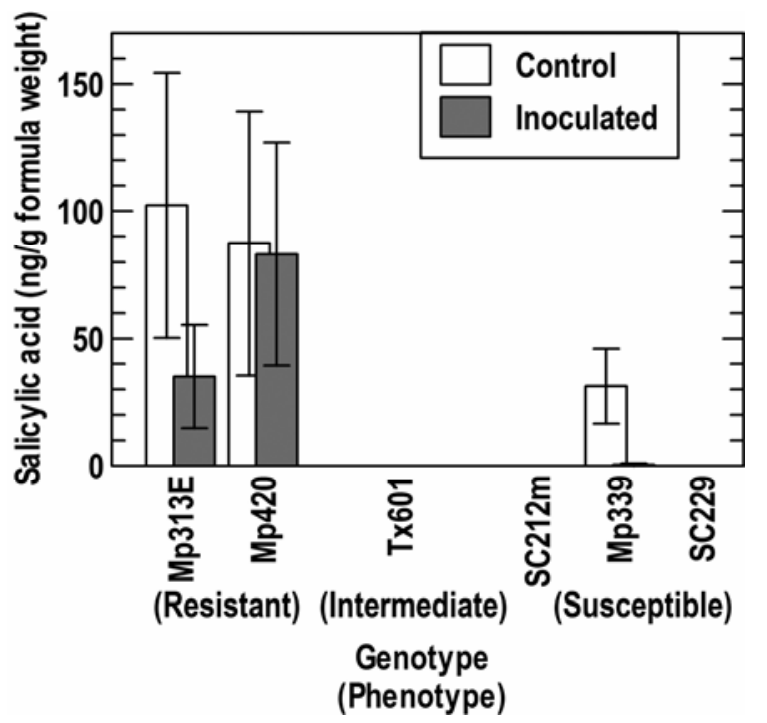

Fig. 5. Salicylic acid levels in embryos 25 days after silk emergence. Each datapoint represents ten replicates. Standard errors are shown. 
the ear approximately 15 DAS and proliferates during ear development and maturation, it seems likely that catalase plays a role in regulating $\mathrm{H}_{2} \mathrm{O}_{2}$ levels during embryo development that may not be necessary in the mature embryo. In the resistant lines, there was little variability in catalase activity at 25 DAS in two years of field experimentation, suggesting that this mechanism is consistent from year to year. Similarly, the resistant lines reacted to fungal inoculation with a $23 \%$ increase in catalase activity $(P=0.02)$, which did not occur in the susceptible lines.

When visualized on a gel, it appeared that only one major isozyme of catalase appeared to be expressed in embryos at 25
W64A

SC212m

Mp313E

Consensus

W64A

SC212m

Mp313E

Consensus

W64A

SC212m

Mp313E

Consensus

W64A

SC212m

Mp313E

Consensus

W64A

SC212m

Mp313E

Consensus

W64A

SC212m

Mp313E

Consensus

W64A

SC212m

Mp313E

Consensus

W64A

SC212m

Mp313E

Consensus

W64A

SC212M

Mp313E

Consensus
1 MTMDPTKFRPSSSHDTTVTTTNAGAPVWNDNEALTVGPPRGPILEDYHLIEKVAHFARER

1 MTMDPTKFRPSSSHDTTVTTTNAGAPVWNDNEALTVGPPRGPILEDYHLIEKVAHFARER

1 MTMDPTOFRPSSSHDTTVTTTNADAPVWNDNEALTVGPPRGPILEDYHLIEKVAHFARER

1 MTMDPTkFRPSSSHDTTVTTTNAgAPVWNDNEALTVGPPRGPILEDYHLIEKVAHFARER

61 IPERVVHARGASAKGFFECTHDVTSLTCADFLRAPGVRTPVIVRFSTVIHERGSPETIRD

61 IPERVVHARGASAKGFFECTHDVTSLTCADFLRAPGVRTPVIVRFSTVIHERGSPETIRD

61 IPERVVHARGASAKGFFECTHDVTSLTCADFLRAPGVRTPVIVRFSTVIHERGPPETIRD

61 IPERVVHARGASAKGFFECTHDVTSLTCADFLRAPGVRTPVIVRFSTVIHERGsPETRID

121 PRGFAVKFYTREGNWDLLGNNFPVFFIRDGIKFPDVIHAFKPNPRSHVQEYWRVFDFLSH 121 PRGFAVKFYTREGNWDLLGNNFPVFFIRDGIKFPDVIHAFKPNPRSHVQEYWRVFDFLSH

121 PRGFAVKFYTREGNWDLLGNNFPVFFIRDGIKFPDVIHAFKPNPRSHVQEYWRVFDFLSH

121 PRGFAVKFYTREGNWDLLGNNFPVFFIRDGIKFPDVIHAFKPNPRSHVQEYWRVFDFLSH

181 LPESLHTFFFLFDDVGVPSDYRHMEGFGVNTYTFVSAAGKAQYVKFHWKPTCGVRCILTD 181 LPESLHTFFFLFDDVGVPSDYRHMEGFGVNTYTFVSAAGKAQYVKFHWKPTCGVRCILTD 181 LPESLHTFFFLFDDVGVPSDYRHMEGFGVNTYTFVSAAGKAQYVKFHWKPTCGVRCILTD 181 LPESLHTFFFLFDDVGVPSDYRHMEGFGVNTYTFVSAAGKAQYVKFHWKPTCGVRCILTD

241 EEAALVGGRNHSHATQDLYDSIAAGSFPEWTLYVQVMDPDTEEQYDFDPLDDTKTWPEDL 241 EEAALVGGRNHSHATQDLYDSIAAGSFPEWTLYAQVMDPDTEEQYDFDPLDDTKTWPEDL

241 EEAALVGGRNHSHATQDLYDSIAAGSFPEWTLYVQVMDPDTEEQYDFDPLDDTKTWPEDL 241 EEAALVGGRNHSHATQDLYDSIAAGSFPEWTLYvQVMDPDTEEQYDFDPLDDTKTWPEDL

301 LPLRPVGRLVLDRNVDNFFNENEQLAFGPGLVVPGIYYSDDKMLQCRVFAYADTQRYRLG 301 LPLRPVGRLVLDRNVDNFFNENEQLAFGPGLVVPGIYYSDDKMLQCRVFAYADTQRYRLG 301 LPLRPVGRLVLDRNVDNFFNENEQLAFGPGLVVPGIYYSDDKMLQCRVFAYADTQRYRLC 301 LPLRPVGRLVLDRNVDNFFNENEQLAFGPGLVVPGIYYSDDKMLQCRVFAYADTQRYRLG

361 PNYLMLPVNAPRCAHHNNHYDGAMNFMHRDEEVRDYYPSRHAPLQAAPPTPLPPRPVAGR 361 PNYLMLPVNAPRCAHHNNHYDGAMNFMHRDEEVRDYYPSRHAPLQAAPPTPLPPRPVAGR 361 PNYLMLPVNVPRCAHHNNHYDGAMNFMHRDEEVRDYYPSRH $\ldots \ldots \ldots \ldots \ldots \ldots \ldots$ 361 PNYLMLPVNaPRCAHHNNHYDGAMNFMHRDEEVRDYYPSRHap1 qaapptp1pprpvagr

421 REKATIRKPNDFKQPGERYF'SWDADRQDRFVRRFAD';LGHPKVSQELRSIWIDLLAKCDA 421 REKATIRKPNDFKQPGERYF:SWDADRQDRFVRRFAD' 'LGPKVSQELRSIWIDLLAKCDA 398 .EKATIRKPNDFKQPGERYF:SWDADRQDRFVRRFAD' 5 LGHPVSQELRSIWIDLLAKCDA 421 rEKATIRKPNDFKQPGERYASWDADRQDRFVRRFAD LGHPKVSQELRSIWIDLLAKCDA

481 SLGMKIATRLNMKANM

481 SLGMKIATRLNMKPNM

457 SLGMKIATRLNMKPYM

481 SLGMKIATRLNMKpnM

Fig. 6. The derived amino acid sequence of cat 3 from W64A (susceptible), SC212m (susceptible), and Mp313E (resistant). Identical amino acids are in black and those that differ are in white. The putative calmodulin-binding regions is enclosed in a black box. The 20 amino acids that are absent in Mp313E are represented by dots. The accession number for cat 3 from W64A is X12539. 
DAS in the inbred lines. Given that Cat3 is observed at the onset of kernel development (Acevedo and Scandalios 1992) and in coleoptiles, we infer that the isozyme that was expressed was Cat 3 . The isozymes Cat 1 and Cat 2 were not detected on the activity-stained gel, and it is unlikely that they contributed significantly to the observed catalase activity. Likewise, it was observed that Cat 3 from the two susceptible lines migrated faster than Cat 3 from the resistant lines. In the case of Mp313E, this was probably to due the 20-aa deletion, which altered its isoelectric point and charge at $\mathrm{pH} 7$. We do not have sequence data for Cat3 from Mp420, and its altered mobility might be the result of a change in molecular weight or charge, or both, or expression of a different allele. Both the activity gel and catalase activity measurement indicated that the two resistant inbreds had higher specific activities than the two susceptible inbreds. In the case of Mp313E, this might have been caused by the 20-aa deletion, which could alter the enzyme's conformation and, hence, its activity.

Steady-state levels of $\mathrm{H}_{2} \mathrm{O}_{2}$ in immature embryos from resistant inbreds were lower than those in susceptible inbreds, which supports the catalase activity data. Since only steadystate $\mathrm{H}_{2} \mathrm{O}_{2}$ levels were measured, we do not know if there was an initial oxidative burst in the embryo in response to $\mathrm{A}$. fla$v u s$. If there was a burst, it may have been attenuated by the higher catalase activity in the resistant lines. Transgenic tobacco lines with reduced catalase activity were found to be more responsive to pathogen attack (Chamnongpol et al. 1998; Mittler et al. 1999). Although higher $\mathrm{H}_{2} \mathrm{O}_{2}$ levels might enhance disease resistance, they also make the plant more susceptible to abiotic stresses (Willekens et al. 1997). Tobacco plants deficient in Cat1 activity had more light-induced leaf necrosis, a compromised ascorbate-glutathione cycle, and increased peroxidase activity (Willekens et al. 1997). These plants were more sensitive to high light and salt levels, ozone, and paraquat-induced oxidative stress (Vandenabeele et al. 2004; Willekens et al. 1997), and it was suggested that catalase serves as a $\mathrm{H}_{2} \mathrm{O}_{2}$ sink that protects the leaves from oxidative damage. A catalase-deficient mutant of barley was unable to overcome stress conditions in the field and had reduced survival and yield (Acevedo et al. 2001).

In addition to having less $\mathrm{H}_{2} \mathrm{O}_{2}$, the resistant embryos had three- to fourfold more SA than the susceptible inbred Mp339. The remaining inbreds had no detectable SA. In tobacco, SA binds to catalase and inhibits its activity (Conrath et al. 1995). This allows $\mathrm{H}_{2} \mathrm{O}_{2}$ and ROS to accumulate and signals the production of various defense-related proteins. In monocots, the response of catalase to SA appears to be different. Rice catalase A, which is expressed in leaves, was insensitive to SA inhibition (Chen et al. 1997). In contrast, SA in roots inhibited catalase B, which shared more sequence similarity with the SA-binding tobacco catalase. Guan and Scandalios (1995) also investigated the effect of SA on the three maize catalases. When CAT2-null maize embryos were cultured on medium containing SA, total catalase activity in the scutella increased in response to low concentrations of SA. This appeared to be due to an increase in Cat1 activity, as there was little change in Cat 3 activity in response to SA. This suggests that maize catalases respond differently to SA than those of tobacco. Of the three maize catalases, Cat 3 has the least similarity to the SAbinding tobacco catalase (Guan and Scandalios 1995), and it is unlikely that SA affects its activity.

If SA does not alter the activity of Cat 3 in the maize embryo, it could protect the embryo from oxidative stress. Endogenous levels of SA in rice leaves are much higher than those in tobacco or Arabidopsis, and consequently, rice is insensitive to exogenous SA treatment (Yang et al. 2004). Transgenic rice plants expressing $n a h G$, the gene that encodes salicylate hy- droxylase, were SA-deficient and contained elevated ROS levels. They were also were hypersensitive to oxidative stress. In these plants, SA probably does not act as a signal for defensegene expression, but it may protect the plant from oxidative stress caused by various abiotic and biotic factors (Yang et al. 2004). The SA concentration in the resistant maize embryos was not as high as that in rice leaves (Yang et al. 2004), but ROS levels are likely to be lower in the developing embryo than in the photosynthetic tissues. The combination of higher catalase activity and SA concentration and lower $\mathrm{H}_{2} \mathrm{O}_{2}$ levels in resistant maize embryos could be detrimental to fungal colonization and aflatoxin accumulation in response to oxidative stress. Lines of Mp313E that are deficient in Cat3 are being generated by back-crossing into Cat 3 null lines, and in the future, we will be able to genetically test the role of Cat 3 in this complex resistance mechanism.

\section{MATERIALS AND METHODS}

\section{Plant materials.}

Aflatoxin-resistant maize inbred lines Mp313E and Mp420, susceptible inbred lines SC212m, Mp339, and SC229, and the intermediately resistant inbred Tx601 were used for this study (Windham and Williams 2002). Both Mp313E and Mp420 were selected for reduced A. flavus infection (Scott and Zummo 1990, 1992), and they usually have significantly lower aflatoxin levels than the susceptible lines (Windham and Williams 2002). Seeds were planted in the field either on 23 April 2001, 17 April 2003, or 20 April 2004, and the emergence of silk was tagged. The plants were self-pollinated. At 15 DAS, half of the tagged ears were spray-inoculated through the silk channel with a suspension of A. flavus (strain GAP 2$8)$ spores in water $\left(9 \times 10^{7}\right.$ conidia/ml $)$. Ears were collected at 18,21 , and 25 DAS, corresponding to 3, 6, and 10 DAI for the inoculated ears. Embryos were excised from the kernels intact, to avoid elevation of catalase levels in response to wounding, and were placed on wet paper towels to prevent dehydration until all the embryos in an ear were collected. Mature (at least 45 DAS), quiescent embryos from inoculated and uninoculated ears were likewise collected by excision with a scalpel. Pericarp was peeled from each kernel individually. The rachis was cleaned extensively of kernel tissues and was sliced in approximately $3-\mathrm{mm}$ sections. The tissues were frozen in liquid nitrogen immediately after collection and were stored at $-80^{\circ} \mathrm{C}$ for protein and nucleic acid extractions. To visualize the different catalase isozymes on a gel, scutella (Cat1 and Cat2) and epicotyl (Cat3) were collected from mature Mp313E seeds 4 days after imbibition (DPI). They were surface sterilized with $10 \%$ Chlorox and were rinsed three times with autoclaved water. The seeds were soaked in autoclaved water for $18 \mathrm{~h}$ and were placed on top of germination paper inside sterile Magenta boxes in the dark for 4 days. At the end of the fourth day, epicotyls were trimmed from the top of the seedlings and the scutella were excised. Tissues were processed immediately and the remaining plants were stored at $-80^{\circ} \mathrm{C}$.

\section{Protein extraction and quantification.}

Samples $(200 \mathrm{mg})$ of tissues were ground either in liquid nitrogen (pericarp and rachis) or in $200 \mu \mathrm{l}$ (embryos and scutella) or $20 \mu \mathrm{l}$ (epicotyl) of $50 \mathrm{mM}$ potassium phosphate buffer, pH 7.0. Each 200-mg embryo sample contained 5 to 20 embryos, depending on their age. For the pericarp and rachis tissues, $200 \mu \mathrm{l}$ of the phosphate buffer was added after grinding. The extract was vortexed for $10 \mathrm{~s}$ and was centrifuged for 15 min twice; the pellet was discarded and the supernatant was retained each time. The resulting extract was kept on ice for protein quantification and catalase activity assays. Protein was 
quantified using the Micro protein determination kit (SigmaAldrich, St. Louis) according to the manufacturer's directions. Absorbance at $750 \mathrm{~nm}$ was measured using a Hitachi 100-80A spectrophotometer.

\section{Catalase activity assay.}

For catalase assays, embryos, pericarp, and rachis from year 2001 and embryos from year 2003 were used. Activity was quantified based on the rate of disappearance of the substrate $\mathrm{H}_{2} \mathrm{O}_{2}$ from a reaction medium containing the protein extract (Beers and Sizer 1952). The $\mathrm{H}_{2} \mathrm{O}_{2}$ concentration in the reaction medium was quantified by the change in absorbance at 240 $\mathrm{nm}$, which was measured using a Cary $3 \mathrm{C}$ UV-visible spectrophotometer and the Cary WinUV kinetics program (Varian Inc., Palo Alto, CA, U.S.A.). A cuvette containing $25 \mu \mathrm{l}$ of crude extract (never frozen) and $875 \mu \mathrm{l}$ of $50 \mathrm{mM}$ potassium phosphate buffer, $\mathrm{pH} 7.0$, was placed in the spectrophotometer and the reading was set to zero. A total of $100 \mu \mathrm{l}$ of $0.2 \mathrm{M}$ $\mathrm{H}_{2} \mathrm{O}_{2}$ was then added to the extract solution and the absorbance was monitored for $2 \mathrm{~min}$. The activity was calculated based on the initial reaction rate during the first $0.25 \mathrm{~min}$ after $\mathrm{H}_{2} \mathrm{O}_{2}$ injection, when substrate concentration was not limiting and the reaction velocity was maximal. Catalase activity was visualized on gels following procedure modified from Clare and associates (1984). Total extract (2, 5, or 25 $\mu \mathrm{l})$ was loaded on a standard nondenaturing polyacrylamide gel (10\% separating and $3.5 \%$ stacking), and the samples were electrophoresed for $18 \mathrm{~h}$. The upper buffer consisted of $50 \mathrm{mM}$ Tris and $50 \mathrm{mM}$ glycine at $\mathrm{pH} 8.9$, while the lower buffer was $100 \mathrm{mM}$ Tris at $\mathrm{pH}$ 7.9. The gel was soaked in 50 $\mathrm{mg}$ of horseradish peroxidase per milliliter (Sigma-Aldrich)

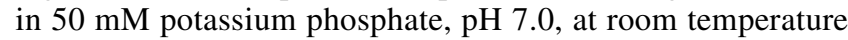
for $45 \mathrm{~min}$ and was rinsed with the phosphate buffer twice. The gel was then treated with $5.0 \mathrm{mM} \mathrm{H} \mathrm{H}_{2}$ for $10 \mathrm{~min}$. The gel was rinsed twice with water, after which staining with 0.5 $\mathrm{mg}$ of diaminobenzidine (Sigma) per milliliter in phosphate buffer was performed. The staining step took a few hours to overnight. The gels were replicated eight times and one was chosen as a representative gel.

Table 1. Primers used in sequencing and polymerase chain reaction

\begin{tabular}{|c|c|c|}
\hline Primer name & Primer sequence $\left(5^{\prime}-33^{\prime}\right)$ & Primer location \\
\hline Ucat3m & $\begin{array}{l}\text { GGCCTCGCGGTCCCATC } \\
\text { CT }\end{array}$ & 131 to 149 \\
\hline Lcat3m & $\begin{array}{l}\text { CGCCTTCACGAATCGGT } \\
\text { CCTGT }\end{array}$ & 1356 to 1377 \\
\hline Cat3L-U & $\begin{array}{l}\text { TGATGGACCCGGCACA } \\
\text { GGAGGAGCAGTA }\end{array}$ & 845 to 872 \\
\hline Cat3L-L & $\begin{array}{l}\text { TTCATGGCGCCGTCGTA } \\
\text { GTGGTTGTTGT }\end{array}$ & 1,145 to 1,172 \\
\hline Mp313E-5_3Sp6F.1 & $\begin{array}{l}\text { CTGCGTCGCGTGGCTGT } \\
\text { GGTTC }\end{array}$ & 765 to 786 \\
\hline Mp313EcDNAF2 & $\begin{array}{l}\text { GTGAGCGCGGCGGGGA } \\
\text { AGG }\end{array}$ & 664 to 682 \\
\hline SC212mcDNASp6R.1 & $\begin{array}{l}\text { TGTACGCGCAGGTGAT } \\
\text { GGA }\end{array}$ & 833 to 851 \\
\hline SC212mcDNAT7F.1 & $\begin{array}{l}\text { AGGAGTACTGGCGGGT } \\
\text { GTTC }\end{array}$ & 526 to 546 \\
\hline cat3-3'ERI & $\begin{array}{l}\text { CGGAATTCCACCACAA } \\
\text { CAACCACTACGAC }\end{array}$ & 1,143 to 1,161 \\
\hline cat3-3'XhoI & $\begin{array}{c}\text { CCGCTCGAGCGGCTATT } \\
\text { CAGCAGAAGCATCAC }\end{array}$ & 1,506 to 1,525 \\
\hline cat3-3 & $\begin{array}{l}\text { TTTTTTGCTGCAGGTGT } \\
\text { CTT }\end{array}$ & 1,753 to 1,771 \\
\hline cat 3 int $1462 \mathrm{f}^{\mathrm{a}}$ & $\begin{array}{l}\text { TGAGGGGGATTGAGGG } \\
\text { GGTTTT }\end{array}$ & 2,329 to 2,350 \\
\hline Cat3int $1462 \mathrm{r}^{\mathrm{a}}$ & $\begin{array}{l}\text { AGTCAGCGCCTCGTTGT } \\
\text { CGTTC }\end{array}$ & 2,790 to 2,769 \\
\hline
\end{tabular}

a These primers were designed from the catalase 3 gene sequence (L05934).

\section{$\mathrm{H}_{2} \mathrm{O}_{2}$ quantification.}

The 25-DAS embryos from year 2004 were used for this analysis. The Correlate-assay colorimetric $\mathrm{H}_{2} \mathrm{O}_{2}$ kit (Assay Designs, Inc., Ann Arbor, MI, U.S.A.) was used to measure $\mathrm{H}_{2} \mathrm{O}_{2}$ concentration. Approximately $500 \mathrm{mg}$ of fresh 25-DAS embryos were ground in $500 \mu \mathrm{l}$ of $50 \mathrm{mM}$ phosphate buffer, $\mathrm{pH}$ 6.0. The mixture was vortexed for $10 \mathrm{~s}$ and was centrifuged for 30 min twice, each time discarding the pellet and recovering the supernatant. Half of the supernatant was reserved for protein quantification, while the other half was passed through a 5,000 molecular weight cut-off column filter (Millipore Corp., Billerica, MA, U.S.A.), to eliminate potential interference from particulates; $50 \mu \mathrm{l}$ of the filtered supernatant was used directly in the assay. A set of standards was run for each assay, and the standard curve was fit to a four-parameter logistic equation as recommended by the manufacturer. A Softmax Pro plate reader (Molecular Devices Corp., Sunnyvale, CA, U.S.A.) was used to measure the optical density at $550 \mathrm{~nm}$, and the corresponding software was employed to perform all the calculations.

\section{SA and JA quantification.}

Embryos collected in 2003 were used for this assay. To extract and detect JA and SA, a previously described method (Tooker and De Moraes 2005), which was modified slightly from Schmelz and associates $(2003,2004)$ was used. Briefly, we derivatized carboxylic acids to methyl esters, which were isolated using vapor phase extraction and were analyzed by gas chromatographic-mass spectrometry (GC-MS), with isobutane chemical ionization using selected-ion monitoring. We quantified amounts of methyl jasmonate (meJA) and methyl salicylate (meSA) using standard curves made with the pure compounds (Sigma-Aldrich), relying on internal standards to confirm derivatization and recovery. We also processed samples without the derivatization agent, to verify that the recovered meJA and meSA were not originally present in analyzed material but were derived from the carboxylic acids. To confirm the identity of meJA and meSA in the samples, extracts were analyzed by GC-MS with electron ionization, comparing retention times and spectra with that of the pure compound.

\section{Nucleic acid extraction.}

Total RNA was extracted from 25-DAS embryos using the RNEasy plant kit (Qiagen, Inc., Valencia, CA, U.S.A.) in accordance with the manufacturer's recommendations, including the optional DNase treatment. Genomic DNA was extracted from $5 \mathrm{~g}$ of young leaves using $10 \mathrm{ml}$ of a CTAB buffer ( $2 \%$ CTAB, 1.4 M NaCl, $100 \mathrm{mM}$ Tris pH 8.0, $20 \mathrm{mM}$ EDTA). The extract was purified with chloroform and was precipitated, using an equal volume of 2-propanol. The precipitated DNA was washed with $70 \% \mathrm{EtOH}$ and was air-dried. Plasmid DNA from clones was isolated using the Qiaprep spin miniprep kit (Qiagen, Inc.).

\section{cDNA, $5^{\prime}$ and $3^{\prime}$ ends amplification, and cloning.}

cDNA and 5'-end DNA were amplified from total RNA using the SMART RACE cDNA amplification kit (Clontech, Palo Alto, CA, U.S.A.), and 3'-end DNA was amplified from genomic DNA. The resulting polymerase chain reaction (PCR) reaction mixtures were electrophoresed on agarose gel, and the desired DNA fragments were recovered by excision from the gel, were purified using Qiaquick gel extraction kit (Qiagen Inc.), and were cloned, using either the pGEM-T easy vector system (Promega, Madison, WI, U.S.A.) or the TOPO TA cloning kit for sequencing (Invitrogen, Carlsbad, CA, U.S.A.). 


\section{PCR.}

All PCR assays were performed in an Eppendorf PCR machine. For reactions that did not involve cDNA amplification, either Platinum Taq DNA polymerase (Invitrogen) or Ex Taq polymerase (Takara, Panvera, CA, U.S.A.) was used. The catalase 3-specific primers used are shown in Table 1.

\section{Sequencing and sequence alignment.}

The Prism 310 genetic analyzer was used for all sequencing with the Prism BigDye terminator cycle sequencing kit (ABI, Foster City, CA, U.S.A.). The sequences obtained were verified against the existing National Center for Biotechnology Information database using the Basic Local Alignment Tool (Altschul et al. 1990). The Lasergene (DNAStar, Madison, WI, U.S.A.) suite of analytical tools was employed for all nucleic and amino acid sequence analyses and comparisons. In all cases, alignment was performed using the ClustalW algorithm.

\section{Cloning of cat3 from Zea mays cDNA and genomic DNA.}

Cloning of catalase 3 was performed using i) cDNA amplified from total RNA from 25-DAS immature embryos, and ii) PCR of genomic DNA extracted from young leaves. The lines Mp313E (resistant) and SC212m (susceptible) were used to clone the coding and untranslated regions. The first group of primers used was designed from the Cat 3 mRNA sequence from line W64A from GenBank (L05934.1); additional primers were designed as sequence information from actual cloning became available. A list of the primers used is shown in Table I. Primer pair Ucat $3 \mathrm{~m}$ and Lcat $3 \mathrm{~m}$ was utilized to clone 1,246 bp of the coding region of Mp313E. The same primer set was unsuccessful in amplifying a similar region in SC212m; hence, the pair Ucat3m and Cat3L-L was used to amplify a 1,041-bp fragment of the coding region. To clone the cDNA ends, primers Cat3L-U and Cat3L-L were initially used to amplify the 3' and 5' ends, respectively, from the two lines, together with their corresponding primers from the kit. Only the $5^{\prime}$ ends of Mp313E and SC212m were successfully cloned from Cat3LL. Initial sequencing of the clones was performed using Sp6, T7, M13F, M13R, and T3 primers. The partial sequences obtained from the ends of the cloned cDNAs were used to design primers more specific to each line, and primer walking was performed to sequence through the cDNA. After several unsuccessful attempts to clone the $3^{\prime}$ ends from the cDNA of both lines, we designed another set of primers with attached restriction enzymes at their 5' end (cat3-3'ERI and cat3$3^{\prime} \mathrm{XhoI}$ ). This primer pair spans the second intron of catalase 3 and should produce a 385-bp fragment from cDNA and a 478bp band from genomic DNA. This primer pair was used to amplify the $3^{\prime}$ end in the genomic DNA. In addition, another reverse primer was designed at the most $3^{\prime}$ end of catalase 3 (cat3-3') to again pair with cat3-3'ERI to complete the $3^{\prime}$ untranslated region of the gene.

\section{Data analysis.}

All data analyses were performed using Excel (Microsoft, Redmond, WA, U.S.A.) and SAS (SAS Institute Inc., Cary, NC, U.S.A.). The procedure glm (general linear model) was utilized for all analyses of variance and the Tukey method for separation of means.

\section{ACKNOWLEDGMENTS}

The authors thank A. Camas for his assistance in primer design, and M. Mescher and G. Felton for reading the manuscript and making many valuable comments. This research was funded by United States Department of Agridculture-Agricultural Research Service through Specific Cooperative Agreement No. 58-6406-1-100 with the Mississippi Agricultural and Forestry Experiment Station.

\section{LITERATURE CITED}

Acevedo, A. and Scandalios, J. G. 1992. Differential expression of the catalase and superoxide dismutase genes in maize ear shoot tissues. Plant Cell Physiol. 33:1079-1088.

Acevedo, A., Paleo, A. D., and Federico, M. L. 2001. Catalase deficiency reduces survival and pleiotropically affects agronomic performance in field-grown barley progeny. Plant Sci. 160:847-855.

Altschul, S. F., Gish, W., Miller, W., Myers, E. W., and Lipman, D. J. 1990. Basic local alignment search tool. J. Mol. Biol. 215:403-410.

Anderson, H. W., Nehring, E. W., and Wichser, W. R. 1975. Aflatoxin contamination of corn in the field. J. Agric. Food Chem. 23:775-782.

Auh, C. K. and Scandalios, J. G. 1997. Spatial and temporal responses of the maize catalases to low temperature. Physiol. Plant 101:149-156.

Beers, R. F., and Sizer, I. W. 1952. A spectrophotometric method for measuring the breakdown of hydrogen peroxide by catalase. J. Biol. Chem. 195:133-140.

Boldt, R., and Scandalios, J. G. 1995. Circadian regulation of the Cat3 catalase gene in maize: Entrainment of the circadian rhythm of Cat 3 by different light treatments. Plant J. 7:989-999.

Bradley, D. J., Kjellbom, P., and Lamb, C. J. 1992. Elicitor- and woundinduced oxidative cross-linking of a proline-rich plant cell wall protein: A novel, rapid defense response. Cell 70:21-30.

Breusegem, F. V., Vranova, E., Dat, J. F., and Inze, D. 2001. The role of active oxygen species in plant signal transduction. Plant Sci. 161:405414.

Brisson, L. F., Tenhaken, R., and Lamb, C. J. 1994. Function of oxidative cross-linking of cell wall structural proteins in plant disease resistance. Plant Cell 70:1703-1712.

Brooks, T. D., Williams, W. P., Windham, G. L., Willcox, M. C., and Abbas, H. K. 2005. Quantitative trait loci contributing resistance to aflatoxin accumulation in the maize inbred Mp313E. Crop Sci. 45:171174.

Chamnongpol, S., Willekens, H., Moeder, W., Langerbartels, C., Sandermann, H. Jr., Van Montagu, M., Inze, D., and Van Camp, W. 1998. Defense activation and enhanced pathogen tolerance induced by $\mathrm{H}_{2} \mathrm{O}_{2}$ in transgenic tobacco. Proc. Natl. Acad. Sci. U.S.A. 95:58185823 .

Chen, Z., Iyer, S., Caplan, A., Klessig, D. F., and Fan, B. 1997. Differential accumulation of salicylic acid and salicylic acid sensitive catalase in different rice tissues. Plant Physiol. 114:193-201.

Chen, Z.-Y., Brown, R. L., and Cleveland, T. E. 2004. Evidence for an association in corn between stress tolerance and resistance to Aspergillus flavus infection and aflatoxin contamination. African J. Biotech. 3:693-699.

Chipley, J. R., and Uraih, N. 1980. Inhibition of Aspergillus growth and aflatoxin release by derivatives of benzoic acid. Appl. Environ. Microbiol. 40:352-357.

Clare, D. A., Doung, M. N., Darr, D., Archibald, F., and Fridovich, I. 1984. Effects of molecular oxygen on detection of superoxide radical with nitroblue tetrazolium and on activity stains for catalase. Anal. Biochem. 140:532-537.

Conrath, U., Chen, Z., Ricigliano, J. R., and Klessig, D. F. 1995. Two inducers of plant defense responses, 2,6-dichloroisonicotinec acid and salicylic acid, inhibit catalase activity in tobacco. Proc. Natl. Acad. Sci. U.S.A.. 92:7143-7147.

Dat, J. F., Inze, D., and Van Breusegem, F. 2001. Catalase-deficient plants: Tools for in planta studies on the role of hydrogen peroxide. Redox Rep. 6:37-42.

Davletova, S., Rizhsky, L., Liang, H., Shengqiang, Z., Oliver, D. J., Coutu, J., Shulaev, V., Schlauch, K., and Mittler, R. 2004. Cytosolic ascorbate peroxidase 1 is a central component of the reactive oxygen gene network of Arabidopsis. Plant Cell 17:268-281.

Dempsey, D., Shah, J., and Klessig, D. F. 1999. Salicylic acid and disease resistance in plants. Crit. Rev. Plant Sci. 18:547-575.

Guan, L. M., and Scandalios, J. G. 1995. Developmentally related responses of maize catalase genes to salicylic acid. Proc. Natl. Acad. Sci U.S.A. 92:5930-5934.

Guan, L. M., and Scandalios, J. G. 1998. Effects of the plant growth regulator abscisic acid and high osmoticum on the developmental expression of the catalase genes. Physiol. Plant. 104:413-422.

Guan, L. M., and Scandalios, J. G. 2000. Hygrogen peroxide-mediated catalase gene expression in response to wounding. Free Rad. Biol. Med. 28:1182-1190.

Jayashree, T., and Subramanyam, C. 2000. Oxidative stress as a prerequisite for aflatoxin production by Aspergillus parasiticus. Free Rad. Biol. Med. 29:981-985.

Kim, J. H., Campbell, B. C., Yu, J., Mahoney, N. E., Chan, K. L., Molyneux, R. J., Bhatnagar, D., and Cleveland T. E. 2005. Examination of fungal stress response genes using Saccharomyces cerevisiae as a model sys- 
tem: Targeting genes affecting aflatoxin biosynthesis by Aspergillus flavus Link. Appl. Microbiol. Biotechnol. 67:807-815.

Kim, J. H., Mahoney, N. E., Chan, K. L., Molyneux, R. J., and Campbell, B. C. 2006. Controlling food-contaminating fungi by targeting their antioxidative stress-response system with natural phenolic compounds. Appl. Microbiol. Biotechnol. 70:735-739.

Kiraly, Z., El-Zahaby, H., Galal, A., Abdou, S., and Adam, A. 1993. Effect of oxygen free radicals on plant pathogenic bacteria and fungi and on some plant diseases. Pages 9-19 in: Oxygen Free Radicals and Scavengers in the Natural Sciences. G. Mozsik, J. Emerit, J. Feher, B. Matkovics, and A. Vincze, eds. Akademiai Kiado, Budapest,

Laloi, C., Apel, K., and Danon, A. 2004. Reactive oxygen signaling: The latest news. Cur. Opin. Plant Biol. 7:323-328.

Lamb. C. J., and Dixon, R. A. 1997. The oxidative burst in plant disease resistance. Ann. Rev. Plant Physiol. Plant Mol. Biol. 48:251-275.

Mahoney, N. E., and Molyneux, R. J. 2004.Phytochemical inhibition of aflatoxigenicity in Aspergillus flavus by constituents of walnut (Juglans regia). J. Agric. Food Chem. 52:1882-1889.

Mellersh, D. G., Foulds, I. V., Higgins. V. J., and Heath, M. C. 2002. $\mathrm{H}_{2} \mathrm{O}_{2}$ plays different roles in determining penetration failure in three diverse plant-fungal interactions. Plant J. 29:257-268.

Mittler, R. 2002. Oxidative stress, antioxidants and stress tolerance. Trends Plant Sci. 7:405-410.

Mittler, R., Herr, E. H., Ovar, B. L., van Camp, W., Willekens, H., Inze, D., and Ellis, B. E. 1999. Transgenic tobacco plants with reduced capability to detoxify reactive oxygen intermediates are hyperresponsive to pathogen infection. Proc. Natl. Acad. Sci. U.S.A. 96:14165-14170.

Mur, L. A. J., Bi, Y.-M., Darby, R. M., Firek, S., and Draper, J. 1997. Compromising early salicylic acid accumulation delays the hypersensitive response and increases viral dispersal during lesion establishment in TMV-infected tobacco. Plant J. 12:1113-1126.

Mylona, P. V., Polidoros, A. N., and Scandalios, J. G. 1998. Modulation of antioxidant responses by arsenic in maize. Free Rad. Biol. Med. 25:576-585

Naidoo, G, Forbes, A. M., Paul, C., White, D. G., and Rocheford, T. R. 2002. Resistance to Aspergillus ear rot and aflatoxin accumulation in maize $\mathrm{F}_{1}$ hybrids. Crop Sci. 42:360-364.

Nakai, K., and Horton, P. 1999. PSORT: A program for detecting the sorting signals of proteins and predicting their subcellular localization. Trends Biochem. Sci. 24:34-35

Payne, G. A. 1998. Process of contamination by aflatoxin producing fungi and their impact on crops. Pages 279-306 in: Mycotoxins in Agriculture and Food Safety. K. K. Sinha, and D. Bhatnager, eds. Marcell Dekker, New York.

Peng, M., and Kuc, J. 1992. Peroxidase-generated hydrogen peroxide as a source of antifungal activity in vitro and on tobacco leaf disks. Phytopathology 82:696-699.

Polidoros, A. N., and Scandalios, J. G. 1998. Circadian expression of the maize catalase Cat 3 gene is highly conserved among diverse maize genotypes with structurally different promoters. Genetics 149:405-415.

Redinbaugh, M. G., Wadsworth, G. J., and Scandalios, J. G. 1988. Characterization of catalase transcripts and their differential expression in maize. Biochim. Biophys. Acta 953:104-116.

Roupakias, D. G., McMillin, D. E., and Scandalios, J. G. 1979. Chromosomal location of the catalase structural genes in Zea mays using B-A translocations. Theor. Appl. Genet. 58:211-218.

Scandalios, J. G. 1994. Regulation and properties of plant catalases. Pages 275-315 in: Causes of Photooxidative Stress and Amelioration of Defense Systems in Plants. C. H. Foyer, and P. M. Mullineaux, eds. CRC Press, Boca Raton, FL, U.S.A.

Schmelz, E. A., Engelberth, J., Alborn, H. T., O'Donnell, P., Sammons, M., Toshima, H., and Tumlinson, J. H. 2003. Simultaneous analysis of phytohormones, phytotoxins, and volatile organic compounds in plants. Proc. Natl. Acad. Sci. U.S.A. 100:10552-10557.

Schmelz, E. A., Engelberth, J., Tumlinson, J. H., Block, A., and Alborn, H. T. 2004. The use of vapor phase extraction in metabolic profiling of phytohormones and other metabolites. Plant J. 39:790-808.

Scott, G. E., and Zummo, N. 1990. Registration of Mp313E parental line of maize. Crop Sci. 30:1378.

Scott, G. E., and Zummo, N. 1992. Registration of Mp420 germplasm line of maize. Crop Sci. 32:137.

Tooker, J. F., and DeMorales, C. M. 2005. Jasmonate in lepidopteran eggs and neonates. J. Chem. Ecol. 31:2753-2759.

Vandenabeele, S., Vanderauwera, S., Vuylsteke, M., Rombauts, S., Langebartels, C., Seidilitz, H. K., Zabeau, M., Van Montagu, M., Inzé, D., and Van Breusegem, V. 2004. Catalase deficiency drastically affects gene expression induced by high light in Arabiodpsis thaliana. Plant J. 39:45-58.

Wadsworth, G. J., and Scandalios, J. G. 1989. Differential expression of the maize catalase genes during kernel development: The role of steadystate mRNA levels. Dev. Gen. 10:304-310.

Willekens, H., Chamnongpol, S., Davey, M., Schraudner, M., Langebartels, C., Van Montau, M., Inze, D., and Van Camp, W. 1997. Catalase is a sink for $\mathrm{H}_{2} \mathrm{O}_{2}$ and is indispensable for stress defense in C3 plants. EMBO (Eur. Mol. Biol. Organ.) J. 16:4806-4816.

Windham, G. L., and Williams, W. P. 2002. Evaluation of corn inbreds and advanced breeding lines for resistance to aflatoxin contamination in the field. Plant Disease 86 232-234.

Wu, G., Shortt, B. J., Lawrence, E. B., Elaine, E. B., Fitzsimmons, K. C., and Shah, D. M. 1995. Disease resistance conferred by expression of a gene encoding $\mathrm{H}_{2} \mathrm{O}_{2}$-generating glucose oxidase in transgenic potato plants. Plant Cell 7:1357-1368.

Xiong, L., Schumaker, K. S., and Zhu, J. K. 2002. Cell signaling during cold, drought, and salt stress. Plant Cell 14:S165-183.

Yang, T., and Poovaiah, B. W. 2002. Hydrogen peroxide homeostasis: Activation of plant catalase by calcium/calmodulin. Proc. Natl. Acad Sci. U.S.A. 99:4097-4102

Yang, Y., Qi, M., and Mei, C. 2004. Endogenous salicylic acid protects rice plants from oxidative damage caused by aging as well as biotic and abiotic stress. Plant J. 40:909-919.

Zhang, A., Jiang, M., Zhang, J., Tan, M., and Hu, X. 2006. Mitogen-activated protein kinase is involved in abscisic acid-induced antioxidang defense and acts downstream of reactive oxygen species production in the leaves of maize plants. Plant Physiol doi:10.1104/pp105.075415. Online publication.

\section{AUTHOR-RECOMMENDED INTERNET RESOURCE}

Maize genetics and genomics database: www.maizegdb.org 